\title{
Global warming versus ozone depletion: failure and success in North America
}

\author{
Sheldon Ungar* \\ Department of Sociology, University of Toronto at Scarborough, 1265 Military Trail, Scarborough, \\ Ontario M1C 1A4, Canada
}

\begin{abstract}
The success of ozone depletion as a social problem is used to examine and understand the relative failure of global warming. Starting with the (aborted) 'hot crisis' of the Greenhouse summer of 1988, this paper tries to show why, despite dire scientific warning, advantages in claimsmaking, and the perceived emergence of strange weather, global warming consistently obtained lesser outcomes. Whereas global warming is a complex and uncertain scientific issue, the ozone hole was associated and resonated with easy-to-understand bridging metaphors derived from the popular culture. The latter problem not only gave rise to a hot crisis, but was also caught up in a cultural whirlwind-a rapidly evolving and progressive sequence of dynamic and often surprising events that surge through a variety of public arenas with a strong conversational and practical presence. Effectively, ozone loss provided a sense of concrete risk with both strong emotional overtones and everyday relevance for talk and action. Global warming, in contrast, is not amenable to bridging metaphors and did not lend itself to a cultural whirlwind.
\end{abstract}

KEY WORDS: Climate change $\cdot$ Ozone hole $\cdot$ Hot crisis $\cdot$ Social construction Resale or republication not permitted without written consent of the publisher

\section{INTRODUCTION}

Global warming is a most paradoxical social problem. It did briefly rise to celebrity status in North America during the Greenhouse summer of 1988explaining that emergence and its rapid decline will occupy the first part of this paper. But since that summer, despite unprecedented scientific warnings and a discernible sense of 'strange weather', it has engendered more concerted opposition and less action than comparable social problems (Ungar 1999). Ozone depletion, a sister problem, rose to public prominence twice, and it resulted first in the virtual termination of supersonic aircraft, and then the groundbreaking Montreal Protocols. Both Ebola Zaire and 10 cases of bovine spongiform encephalopathy (BSE) also touched off 'hot crises', a concept that is discussed below. Drawing on comparisons with reasonably cognate issues (ozone depletion foremost, the nuclear arms race, as well as Ebola and BSE), this paper goes on to examine why global warming has remained a lesser social problem in a protracted limbo despite scientific fears that it is the greatest threat that humankind faces. ${ }^{1}$

This paper aims to draw together, summarize, and advance an ongoing sociological research program comparing global warming and ozone loss. It addresses some fundamental issues in the sociology of social problems, but tries to render the analysis clear to scientific experts without any sociological background. At the same time, it aims to be somewhat practical and to sharpen our understanding of climate change as a specific issue with a historical trajectory that does not readily mesh with the public and issue cultures that surround it in North America.

\footnotetext{
${ }^{1}$ Thus the Kyoto Treaty, which calls for reductions that fall far short of what scientists believe necessary, has not been passed by the US and only 'voluntary' actions have been agreed to. The Canadian federal government and provinces remain split on the agreement as well
} 


\section{COMPARATIVE AND ANALYTIC STRATEGIES}

This paper compares global warming and ozone loss because the parallels between the two are sufficiently remarkable that they have been compared to a natural experiment (e.g. Rowlands 1995). On a scientific level, both are global environmental threats pertaining to the atmosphere. Both are claimed to result from anthropogenic emissions. Both are slow-onset problems that portend potentially apocalyptic outcomes. Both are 'invisible' as such and can only be detected through assembling scientific research and claims. Effectively, both must be socially constructed, and this paper focuses on their potential as saleable problems.

The 2 problems also intersect practically, since CFCs are a potent greenhouse gas. But there are additional intersections that are nothing less than intriguing. The first, as elaborated below, is their coincident timing. Probably as a result of these 2 prior intersections, the 2 issues are also linked and often confounded in the public mind (Kempton et al. 1995). But the ozone problem is not just a model for climate change among the public. Social scientists, environmentalists and the policy community widely regard the ozone example as a 'success story' and a 'blueprint' for efforts to control greenhouse gases (Parson 1993, Grundmann 2001, p. 3). In effect, their shared scientific characteristics, combined with fortuitous timing, have been parlayed into cognitive, political and policy overlaps. From a social constructionist perspective, the two are coupled regardless of the differences that can be pointed out.

Perhaps the one sticky difference has been the claim that ozone loss was an 'easy' issue to solve. But Grundmann (2001, p. 207), who has done the most in-depth study of the policy process surrounding the ozone threat, concludes that 'the case was anything but simple.' One of his central arguments is that the ultimate costs of controls were largely unknown when the Montreal Protocols were agreed upon. He also cogently argues that success on this issue was quite puzzling and not to be taken for granted.

Both of the issues under review are of global scope and can be approached at various levels of analysis. Parson (1993) examines the role of international negotiations and institutions for the success of the ozone issue. Grundmann (2001) draws on a variety of ideas but ultimately focuses on policy networks and their 'speakers' in the ozone controversy. This paper, in contrast, compares the paths of both problems, and it does so from a social constructionist perspective that examines claimsmaking, the media, and public attention and reactions. The present analysis does not invalidate nor supercede these others, but shifts the spotlight and assigns different 'weights' to key factors. Thus at several vital points in the analysis I point out how the present comparative and constructionist perspective renders some of the claims made by Grundmann questionable.

\section{GLOBAL WARMING AS A FAILED PROBLEM}

According to the social constructionist perspective, even a social problem that seems purely objective, as in damage to the ozone layer, can be shown to be 'inevitably subjective' (Hannigan 1995). No condition is a social problem unless groups with some power consider it one and try to market it. Constructionists focus on claimsmaking activities, asking not what makes a claim valid but what makes it viable.

The focus on how participants' activities constitute the viability of claims has been criticized for 'not specifying other grounds of a problem, and not articulating why one set of claims rather than another is deemed worthy of social attention' (Fritz \& Altheide 1987, p. 474). The research program reviewed here faults constructionists for examining successful social problems and largely ignoring failed ones. For example, while claimsmaking by the US military-industrial complex (MIC) is used to explain the hot crisis unleashed by Sputnik, researchers tend to ignore the apathetic public responses to claims made about 18 or so other 'nuclear gaps' in the Soviet favor (such as the ostensible 'bomber gap,' or the 'antiballistic missile gap'). This research demonstrates that claims were viable when they could piggyback on dramatic and startling real-world events - the launch of Sputnik or the Soviet invasion of Afghanistan-and not simply because theoretical gaps were promoted by the MIC (Ungar 1990, 1992b).

The importance of dramatic real world-events is underscored by the Greenhouse summer of 1988. Prior to that summer, climate change was an unsuccessful problem. According to Schneider (1989, p. 192), 'with the hundreds of such [media] stories plus the government forums that had occurred since 1970, by 1987 I assumed that the greenhouse effect was pretty much a household term. As things turned out, there was a long way to go.' Effectively, the claims made about the problem did not resonate or find a receptive audience.

\section{THE (ABORTIVE) HOT CRISIS OF 1988}

Research on claimsmaking before, during and after the summer of 1988 reveals that global warming became a celebrity issue in 1988 because it piggybacked on concatenating real-world events that were felt by the person in the street (Ungar 1992a). North 
America suffered record-breaking heat, dangerous air pollution levels over cities, and a crop-destroying drought that reduced the US grain harvest to below consumption for the first time. There was an increase in the frequency and intensity of storms, with hurricane Gilbert termed a 'super hurricane'. Forest fires were the worst of the century and gained particular prominence with the fire in Yellowstone National Park. The impact of 1988 was global: Bangladesh suffered the worst flood of the century, and Europe witnessed the spectacle of thousands of dying seals and a red-tide driven exodus of tourists from long stretches of Italian coastland. Rather exceptionally, this global impact was given extensive media coverage in the US.

Schneider (1989, p. 203) provides an apt summary: 'In 1988, nature did more for the notoriety of global warming in fifteen weeks than any of us [scientists] or the sympathetic journalists and politicians were able to do in the previous fifteen years.' That summer fulfilled the conditions for a 'hot crisis', a concept developed to explain reactions to Ebola Zaire. According to Ungar (1998b),

'Whereas journalists tend to view crises as any kind of trouble at all, hot crises entail dread-inspiring events that are developing in unpredictable ways and are seen as having the potential to pose an imminent personal threat to specific populations. Hot crises are startling, as presumed invulnerabilities appear to be challenged. A palpable sense of menace puts the issue 'in the air', as unfolding events are watched, discussed and fretted over.'

Ebola engendered a hot crisis because of its potent dread factor (gruesome and almost certain death with blood oozing from every orifice) coupled with a sense of personal threat due to the much-touted menace of 'instant-distant infections', the claim that we are just 'a plane ride away' from a 'chain of lethal transmission'.

The acute episodes of collective fear unleashed during a hot crisis lead, in turn, to accelerated demands on the political arena. Demand acceleration entails urgent calls for extraordinary responses - solutions that tend to be costly, simplify real problems to the point of caricature, seek to leap-frog the prevailing processes for evolving solutions, and can verge on the draconian. Nuclear crises had real effects that redounded on the education system, the American civil religion, and of course nuclear buildups that were gratuitously massive (Ungar 1991). And a few case of BSE gave rise to a marauding 'hot potato' that befell, consecutively, British farmers, the British government, and finally the European Union (Ungar 2001). But while the Greenhouse summer of 1988 evoked political promises in response to accelerated demands-President Bush Senior pledged a 'White House effect' — there was no follow-up on these promises and the hot crisis petered out without any clear long-term consequences. At best, the public now had some awareness of the threat, but tended to misunderstand it (Mazur \& Lee 1993).

\section{THE PARADOXICAL STATUS OF GLOBAL WARMING}

The aforementioned 1992 study focused on the galvanizing effects of dramatic real-world weather impacts. Subsequent events and attendant analyses suggest that the hot crisis of the summer of 1988 depended on the weather and other opportunities that were not as obvious or stressed as much in the immediate aftermath of that summer. Consider the ensuing paradoxes, which are thrown into relief by comparison with other issues examined here:

- the 'demand attenuation process' whereby the crisis subsided even before the weather returned to a 'normal' state (Ungar 1992a);

- the immediate and then the long-term backlash against global warming, which is unprecedented among the selected issues; and

- the relative lack of international agreements and particularly political responses and actions, especially in the face of dire scientific warnings and the seeming emergence of 'strange weather' (Ungar 1999).

All 3 points indicate that the hot crisis of the summer of 1988 lacked staying power and failed to provide a critical 'discourse moment' that fed into and provided a map for grasping or organizing subsequent events. ${ }^{2}$

Critical to this analysis is the sense of strange weather that emerged in North America during the 1990s. For example, 1993 was dubbed the year of 'Killer Weather' and the Mississippi River rose to levels that, as Time Magazine noted, Mark Twain could never have imagined (see Ungar 1999). Consider here systematic data on media coverage of extreme weather from 1968 to 1997.

Data compiled from the Vanderbilt University's Television News Archives were used to construct an extreme weather index based on the national news broadcasts of the 3 major American television networks (ABC, CBS, NBC). The index combines all news coverage of heat waves, droughts, floods, and hurricanes (Ungar 1999). As shown in Fig. 1 (top timeseries), there are sizeable year-by-year fluctuations in the level of coverage. Until 1988, noticeable peaks in coverage occur at best every 5 or 6 yr. But between 1992 and 1996, peak coverage is found in 4 of the $5 \mathrm{yr}$.

\footnotetext{
${ }^{2}$ In contrast, the author's pursuit of emerging disease coverage in the media reveals that virtually all attempts to create fearful scenarios draw on Ebola (Ungar 1998b)
} 


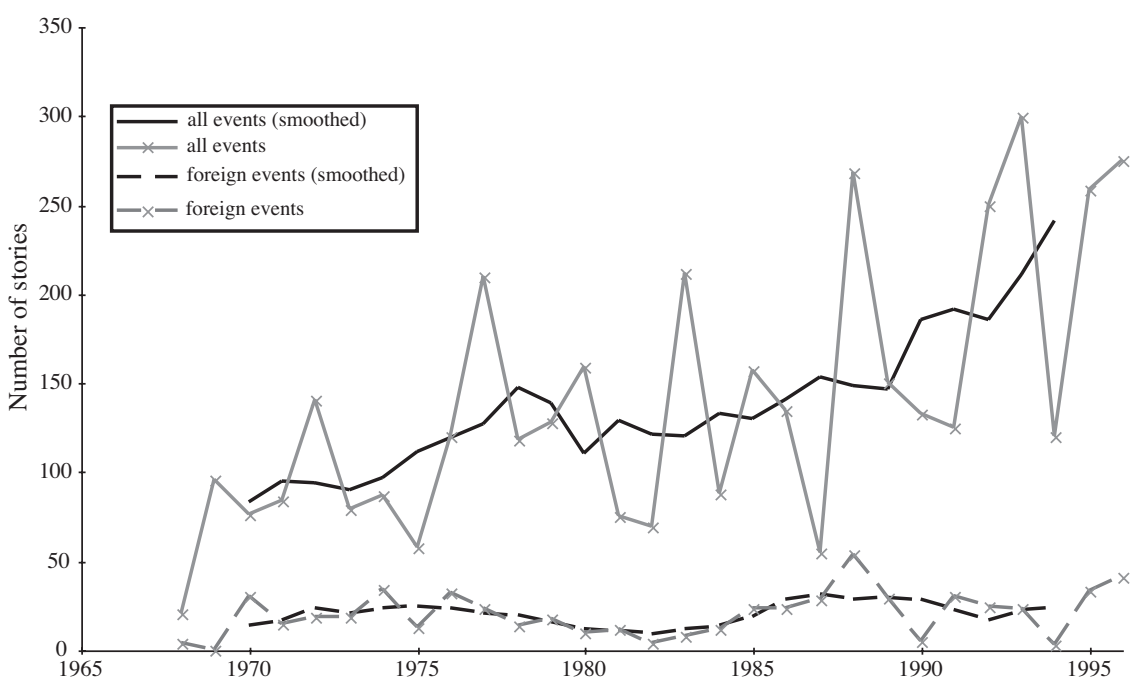

Fig. 1. Index of extreme weather coverage on US television network news
The relative indifference with which this strange weather was received - it made grand television viewing, but failed to galvanize appreciable dread or concern-suggested that factors beyond extreme weather impacts were critical for the hot crisis of 1988. The idea of watching for concatenating 'signs' of global warming seemed realistic after 1988 (Bernard 1993, Ungar 1995); yet in subsequent years the increased media coverage of extreme weather events combined with large increases in weather-related insurance losses did not provide the expected greenhouse signal and the attendant spike of attention with accelerated political demands.
Given that the numbers of stories in these 4 yr greatly exceed all previous years, excepting 1988, the results indicate that a sense of strange weather has been in the air since at least 1992.

Fig. 2 presents the annual number of stories devoted to global warming and the number of these that are weather-pegged. When the frequency of annual stories devoted to global warming is compared with the extreme weather index found in Fig. 1, it is clear that there is no relationship between the 2 variables. Thus if 1993 was the year nature went mad, it elicited negligible coverage of global warming. Moreover, and somewhat surprisingly, weather-pegged stories on global warming are extremely rare.

Further evidence of dissociation between the weather and climate change is suggested by the coverage of international events (Fig. 1, bottom time-series). Overall, concern about climate change is likely to be strengthened by the realization that extreme weather impacts are global rather than just national or even local phenomena. Increased international coverage would both corroborate and generalize the sense of strange weather. However, the results reveal no trend toward increased coverage of foreign extreme weather impacts; indeed, there is a relative decrease in these stories, since the total number of stories on extreme weather rises steeply in the 1990s.

\section{THE ‘ISSUE CULTURE' SURROUNDING THE ATMOSPHERE}

In sum, whereas Americans were bombarded by media reports of extreme weather in the 1990s, they did not generate noticeable concern about global warming. This suggests that the hot crisis of 1988 had as much to do with the ripe issue climate that congealed around the atmosphere as with extreme weather impacts themselves. Recent theory and research point to the centrality of issue cultures and their ensemble effects in determining social problem outcomes (e.g. Mazur \& Lee

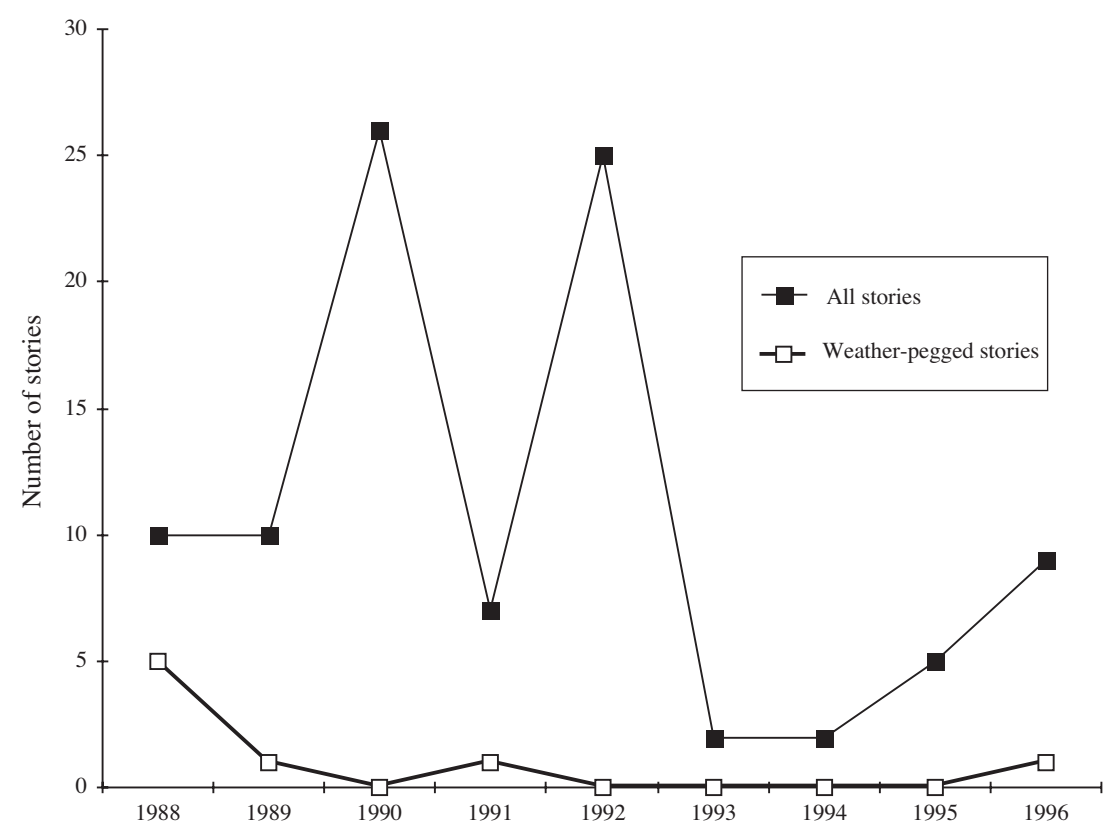

Fig. 2. Annual coverage of global warming on US television network news 
1993). Issues often appear in batches, and their common presence can congeal into dominating cultural themes which provide images, symbols, and selection principles with which specific social problems resonate, while others do not. The public, politicians, and so on are more receptive to social problems that mesh with current public issue cultures than to those problems that are not engaged by them. (Thus anything even remotely related to terrorism commands attention in the US since $9 / 11$; to sell an issue, it is all but essential to find such a connection.)

Starting around 1980 and continuing through the decade, an issue culture built up around the atmosphere as a number of problems from this domain rose in tandem or quick succession. This culture was primed by the popular theory that a comet striking Earth caused climatic change that led to the extinction of the dinosaurs. It was then stoked by fears of nuclear winter. (It may be difficult now to recall just how irresponsible President Reagan's early nuclear talk was; Ungar 1990.) But the Cold War began to wind down after 1985, just in time for a hot crisis stoked by the surprise discovery of the ozone hole. Here the timing is remarkable. The ozone problem peaked in the political arena between 1985 and 1987 and was 'resolved' just in time for its sister issue, global warming, to be carried along and become a celebrity problem (Mazur \& Lee 1993). The latter was also assisted by a peaking of public concern for the environment in general. Recycling became a commanding theme in North America in 1988 and 1989 (Ungar 1998c), and Dunlap \& Scarce (1991, p. 652) speak of a 'miracle' of public opinion during those years.

But this ripe issue culture did not persist. Early on in the 1990s, even before the 1992 Rio Earth Summit, both global warming and the environment itself were rapidly becoming lesser social issues that occasioned only sporadic attention (Ungar 1996). In the decade following Rio, global warming was substantially reconfigured as a research problem and routinized in international negotiations that, particularly in the US, have produced few concrete actions and much acrimonious debate. Given the coincident timing of the ozone hole and the Greenhouse summer of 1988, combined with the synergistic effects of a ripe issue culture, much more was anticipated (cf. Grundmann 2001):

'...perhaps one reason expectations were so high [for global warming] is the success of negotiating the Montreal Protocols... Environmental NGOs and negotiators moved from ozone to climate change, many of them expecting the second shot to be much like the first one (Rowlands 1995, p. 236).'

The rest of this paper undertakes a detailed comparison of the trajectories of global warming and ozone depletion in order to understand the differential outcomes achieved by the 2 sister issues.

\section{SIMILARITY, DISSIMILARITY AND DISTINCT TRAJECTORIES}

As noted at the start of the paper, the parallels between global warming and ozone loss are sufficiently remarkable to afford comparisons akin to a natural experiment. These similarities notwithstanding, there were striking dissimilarities in outcomes. Following the surprise discovery of an ozone hole over Antarctica, it took just 2 yr to formulate the Montreal Protocols. This was not only the first international treaty on a global ecological problem, but is widely regarded as a landmark regime and prototype for future negotiations (e.g. Litfin 1994, p. 5). Its significant innovations include automatic provisions for review (these have led to a ratcheting up of the agreement) and funding by rich nations for adaptations by poorer nations. The US took the lead in negotiating these protocols, and US corporations were supportive and began an 'energetic pursuit' of substitute chemicals. In contrast, the US has steadfastly resisted action on global warming. Its opposition led to a minimal agreement at Kyoto, and continued US inaction leaves that agreement in something of an international limbo. ${ }^{3}$ Canadians also remain split on the issue.

Public responses mirrored political ones. With the ozone threat, there have been a number of successful consumer boycotts, notably of aerosol cans and of McDonalds $^{\circledR}$ (and others) for the use of Styrofoam ${ }^{\circledR}$. A mobilized public was also instrumental in getting European nations to agree to controls (e.g. Rowlands 1995, p. 229). In the contrasting case of global warming, US consumers have not made any efforts to reduce energy consumption. Rather, and in tandem with industry, they have steadily eroded the conservation measures created in response to the 2 oil crises. Statistics reveal that people are driving more, using more gas, and getting lower mileage (Tagliabue 1998). The last statistic is particularly significant, for it indicates that the fastest-growing segment of vehicle sales is in the low mileage vans, sports utility vehicles, and pickup trucks.

These differential outcomes require explanation. Clearly, not all the factors that might be involved can be discussed (cf. Ungar 1995, 1998b, Grundmann 2001). Following the constructionist tradition, the first factor examined is the claimsmaking surrounding each issue. The analysis then turns to the trajectories

\footnotetext{
${ }^{3}$ Whereas the US, Japan and Russia are resisting Kyoto, the European nations are pressing ahead on the plan. This difference merits inquiry, especially since Grundmann (2001, p. 159) claims that 'the CFC problem in Germany entered public discussion via the detour of climate change.' However, he does not explain the ordering in Germany
} 
of the 2 problems. It argues that social problems have-and ongoingly accumulate-scientific, economic, and political characteristics that become 'sticky' and impart a limited trajectory to the problem. Claimsmakers are both impelled and constrained by the historical claims, understandings and practices that adhere to a problem. Moreover, they must try to mesh this trajectory with the public and issue cultures that prevail in various public arenas. It is in these realms that ozone loss had a signal advantage over its sister issue.

\section{THE ROLE OF CLAIMSMAKING}

The social constructionist perspective relates issue success to the quantity and quality of claimsmaking it engenders. Thus over $25 \mathrm{yr}$ of research on the agendasetting hypothesis demonstrates that the amount of media coverage of an issue is a major determinant of public awareness (McCombs \& Shaw 1993). Events that figure prominently in the media seem to be more 'available' or retrievable from memory and are regarded as more 'representative' than events that attract less coverage.

Quantity of coverage does not appear to be decisive in the present case. Data presented by Mazur \& Lee (1993) reveal that over the peak of their overlapping issue attention cycles (1987-1991), climate change attracted more than twice as many stories as ozone depletion in the Readers' Guide to Periodical Literature and on the evening news broadcasts of the 3 major US television networks. While they received about the same amount of coverage in the New York Times, climate change averaged more than twice as many Congressional hearings and publications as did ozone depletion. Finally, more prominent scientists and scientific organizations have come out over climate change than ozone depletion. Statements pertaining to the former have been signed by a majority of living Nobel Laureates, and the Royal Society of London broke $300 \mathrm{yr}$ of official silence on public topics to issue a warning about climate change. Ozone depletion did not attract laureates or create media stars like Stephen Schneider.

These results cast some doubt on Grundmann's (2001) claim that policy networks with speakers high in trust and credibility were the key movers in the success of the ozone problem. While he talks about 'the tremendous amount of media attention' the issue received, which 'almost automatically gets [it] onto the political agenda' (Grundmann 2001, p. 114), this is rendered less obvious by comparison with the results for global warming. To make matters worse, ozone coverage in the media peaked in 1988 and 1989-after the
Montreal Protocols were hammered out (Ungar 1998a). The ensuing discussion of the effects of the ozone hole will suggest that the weight of public reactions has to be increased relative to Grundmann's focus on advocacy alliances.

A further possibility is to focus on rhetoric (Hannigan 1995). Perhaps the rhetorical strategies designed for ozone depletion did the trick. Thus it is clear that the ozone 'hole' was an exaggeration and that satellite pictures were doctored and colored to make them more graphic. However, there remains the question of why the hole - in Britain it is often referred to as a 'crater' could bear such an explanatory burden? What, in other words, rendered it so unique and worthy of attention and concern?

To give credence to a rhetorical analysis, it must be simultaneously maintained that the (more prevalent and timely) rhetoric surrounding global warming missed the boat. This sort of claim, of course, is almost immune to evidence. Commentators would need to know the range of claims that were assayed. More difficult still, they would have to judge which unmade claims were in fact 'viable' and hence could have been successfully promoted.

Ongoing perusal of scientific, media, and environmental claims about global warming since 1988 casts doubt on the missed opportunities position. Rather, analysis suggests that claimsmaking pertaining to this issue resembles trial balloons. A multiplicity of metaphors (the 'heat trap', 'earth fever', 'dead heat') and attempted linkages with other congenial issues (ozone depletion, strange weather, emerging diseases, biodiversity, and clean air and a 'no-regrets' policy) can be found. Essentially, claimsmakers are continually searching for striking formulations that will be taken up, 'resonate', and mobilize actions. Instead of missing the boat, it may well be that the boat never docked! ${ }^{4}$

\section{THE (HANDICAPPED) SCIENTIFIC TRAJECTORY OF GLOBAL WARMING}

Social problems have origins and developmental histories that are not superfluous. Rather, they develop trajectories that are conceptualized as a flight 'corridor' (Ungar 1998a). The corridor is the space within which claimsmakers running a problem encounter the least

\footnotetext{
${ }^{4}$ Grundmann (2001, p. 205) suggests that the 'consensus strategy' of the science of global warming results in a 'mean risk' approach which opens the field to contrarian scientists. However, it is not clear how this has rendered the opposition more potent. Moreover, my ongoing perusal of media coverage of global warming indicates that they have not downplayed extreme impacts
} 
resistance. The corridor allows for artful activity, as it affords a range of choices beyond a single, unique path. It also implies constraint, as practical developments and oppositional voices tend to create turbulence as the boundaries of the corridor is seen to be violated. In other words, given a trajectory, social problem definitions are not, at any particular moment in time, either infinitely malleable or simply fixed.

The scientific trajectory of global warming seemingly presents a number of unique challenges. I begin with a concrete example to illustrate this and the related problem of meshing with issue cultures. Then I approach the science more generally and comparatively, with the aim of showing the relative advantage that was held by ozone loss.

Scientists customarily define global warming as a future-oriented problem, with effects predominately predicted for the middle or end of the 21st century. From the start of concerted scientific claimsmaking in the late 1970s, a future orientation became a definitive characteristic of this problem for numerous and overlapping reasons. First, the doubling of pre-industrial $\mathrm{CO}_{2}$ levels was not predicted to occur until about 2060. Doubling can be considered a benchmark measure, a binary that is more intuitively clear than claiming that levels have increased by, say, $40 \%$. Doubling was also significant because scientists held that their computer models of the climate system were too primitive to deal with smaller changes on a shorter-term basis. At the time, scientists were only beginning to collect the longterm observations that could be used to document climate changes over time. In order to generate concern, the size of impacts delineated in scientific scenarios had to be sufficiently large or visible on a human scale (e.g. a meter of sea-level rise, rather than a few centimeters) that they would take decades to occur on a natural scale (e.g. Bernard 1993). Finally, since computer models only predict general tendencies, particular extreme weather events cannot be directly attributed to climate change.

Efforts, of course, have been made to reverse this trajectory and to claim that 'strange weather' and other evidence are signs that climate change is already occurring. But when James Hansen claimed during the 1988 heat wave that global warming was upon us, there was such a concerted reaction that it stands as a cautionary tale (see Ungar 1992a). In the scientific and political commentary on the issue, his temerity stands as nothing less than an act of infamy, and most scientists continue to deny inferences that try to link observed events with global warming.

A future orientation is thus a 'sticky' element of the scientific trajectory of global warming. The idea recurs so regularly that it is a definitive, unavoidable, and undeniable definitional feature of the problem. But from the point of view of selling the problem, a future orientation creates a clear discursive liability. Specifically, concern about the future is discounted in institutional thinking and in virtually every public arena (Cline 1992). ${ }^{5}$ Since people are apparently unwilling to sacrifice much for future generations, selling a futureoriented threat is extremely difficult. Indeed, economists routinely devalue the future in their calculations. Given its wide purview, future discounting can be regarded as a cultural given that results in expectable limitations on the marketability of future-oriented social problems. Certainly the distant nature of the threat is routinely referenced by climate activists who bemoan its existence even as they search for ways to render the envisioned fate of our grandchildren real and vivid.

More generally, the science of the greenhouse effect is beset by striking uncertainties and complications (Ungar 1995). So great are the uncertainties, especially when it comes to applying the science in the political realm and to high-stake decision-making, that climate science has been termed 'postnormal' science. Applying this concept, Bray \& von Storch (1999) document sufficient uncertainty among climate scientists, especially concerning the science-public interface, that they ask whether the reporting of this science serves to discredit both the science and journalism in the eyes of the public? A recurring source of confusion and backlash is illustrated by 'transient impact-estimates' (Ungar 1995). A key example of these comes from the succession of downward revisions of projected sealevel rises. As global circulation models developed, a once predicted $30 \mathrm{ft}$ (approx. $9 \mathrm{~m}$ ) rise in sea level has been reduced to about a $1 \mathrm{ft}(30 \mathrm{~cm})$ rise. Shifts like this provide a field-day for opponents, who variously claim that scientists are crying wolf or just do not know what they are talking about.

In this regard, Bray \& von Storch (1999, p. 453) observe that, 'According to Lewis (1990), one widely held view in this regard is that the public should be excluded from the policy process associated with risks since the public are generally too ill informed to make rational choices.' Ungar (2000) asserts that scientific ignorance rather than knowledge is the starting point and norm for most issues. Pockets of observed public knowledge are exceptional and require specific explanation. Thus considerable research reveals that the public has very limited scientific knowledge about global warming and tends to confound it with ozone

\footnotetext{
${ }^{5}$ NIMTOO-a common environmental and media acronym for Not in My Term of Office - further illustrates how political actors treat even short-term future considerations with less significance than the more 'vivid' and 'pressing' problems operating in real time
} 
depletion, which has arrived in the public consciousness (Ungar 1998a). In the same vein, and in contrast with ozone loss, the public has virtually no knowledge of the policies being debated for global warming.

But why did ozone loss, an issue that received less media attention and less prestigious claimsmaking than global warming, anomalously arrive and break through the veil of demonstrated scientific illiteracy? According to Kempton et al. (1995, p. 68),

'...it appears that Americans are now familiar with ozone depletion, an earlier and simpler concept with fewer causes and fewer consequences than global warming. The assimilation of the greenhouse effect to a model of ozone depletion is an example of syncretism, a process often documented by anthropologists in which new information is assimilated to fit existing familiar concepts...'

While the thrust of this analysis is sound, the question of why ozone loss is 'simpler' is not addressed. Certainly the public's level of scientific illiteracy is sufficiently high that the chemistry of ozone depletion is no more accessible than the chemistry (or physics) of global warming. That the arrival of ozone depletion is not self-explanatory is further indicated by the findings that, while the public grasped the impact of aerosol cans and Styrofoam ${ }^{\circledR}$, they generally fail to associate the risk with refrigeration and air conditioning. In other words, while global warming is undoubtedly more complex than ozone depletion, no reason or evidence is adduced to show that the ozone problem is simple-and not just somewhat simpler but still largely incomprehensible.

In the ensuing analysis, the success of the ozone problem is explained through the metaphor of a whirlwind - a rapid and concatenating series of events that irresistibly sucks people in. For a whirlwind to develop, it appears that an issue must be blessed with bridging metaphors to the popular culture allied with spiraling sequences of events that people encounter in an irresistible and concrete way.

\section{BRIDGING METAPHORS}

The signal advantage of the ozone hole is that it can be encapsulated in a simple and widely familiar 'penetration' metaphor. Stated succinctly, the hole leads to the increased bombardment of the earth by lethal rays. The idea of rays penetrating a damaged 'shield' meshes nicely with abiding and resonant cultural motifs, including 'Hollywood affinities'. These range from the shields on the 'Starship Enterprise' to 'Star Wars', which encompasses both the megahit movies and the Strategic Defense Initiative. The penetration model is also ubiquitous in video games and children's television shows. In addition, it is allied with a theory that has arguably spawned more public interest more rapidly than any other recent scientific idea: the claim that an asteroid striking the earth 65 million yr ago caused the disappearance of dinosaurs (Clemens 1986).

It is these pre-scientific bridging metaphors built around the penetration of a deteriorating shield that render the ozone problem relatively simple. That the ozone threat can be linked with Darth Vader means that it is encompassed in common-sense understandings that are deeply ingrained and widely shared. The linkages are neat, direct, and tightly coupled. They also provide a resource for lay theorizing. That is, if a popular cultural template affords an appropriable theory, an 'object-to-think' with or that can be 'played with' - as in Freudian analysis of dreams - it has the capacity to go beyond the scientific domain and to capture the imagination of the public at large (Turkle 1999). It is conversational presence, encompassing things such as talk radio and informal talk related to mundane practices, rather than media coverage per se, that can put an issue in the air and let it acquire a life of its own.

The importance of mundane metaphors that ordinary people are able to think with can be seen in a comparison with climate change. The difference can be first grasped in the fundamental metaphor used to frame each problem. It is apparent to anyone that the 'hole' or 'crater' is an aberration, something that a protective shield should not have. The greenhouse effect, in contrast, is a benign and essential natural phenomenon. Global warming (or climate change) is an extension of this phenomenon, creating the problem of finding the human 'fingerprint' amidst highly variable and complex natural processes. ${ }^{6}$

At a more fundamental level, there are apparently no ready-made metaphors in the popular culture that mesh with and provide a simple schematic for understanding the science of climate change. Even a minimally coherent account of why climate change is a threat involves a series of loose postulates that span several scientific fields and transcend both the public's understanding of science and the information carrying capacity of most of the mass media. Thus the model begins with an excess accumulation of various chemicals in the atmosphere (the main culprit, carbon dioxide, was already present at lower levels of concentration); these chemicals lead to the excess trapping of the Sun's rays after they rebound from the Earth's surface;

\footnotetext{
${ }^{6}$ Scientists use 'fingerprint' to capture the difficulty of finding the human signature. People are more likely to notice a footprint, and a large one at that
} 
this lead to forecasts of a several degree rise in temperature over the first half of this century; rising temperatures, in turn, lead to predictions of sea-level rise and an increase in extreme weather events; and finally, these events are expected to impact on forests, agriculture, and so on, with the bulk of the impacts - but not all of them-expected to be negative.

In the absence of a bridging metaphor that encapsulates a streamlined version of this model, it is hardly surprising that greater media coverage of climate change has not brought dividends in understanding. Whereas practically every space-based video game deals with the direct and typically dire consequences following from the penetration of shields, there are no games that are even remotely linked to the indirect rebound effects of climate change. To put it somewhat differently, ozone has clear affinities with core elements of the popular culture, while climate change is an 'outsider'.

\section{THE WHIRLWIND EFFECT}

The greater comprehensibility of the ozone hole would not have mattered if the issue was not caught up in a cultural whirlwind. The attention economy suggests that people are highly selective in the information they take time to notice and process (Ungar 2000). Bridging metaphors linked to the popular culture afford an opportunity to learn about an issue, but they do not provide the effective motivation to do so. As a result of timing and luck, ozone depletion gave rise to a series of overlapping concerns that played out in daily life.

A cultural whirlwind involves a rapidly evolving and progressive sequence of dynamic and often surprising events that create a vortex that hurls through a variety of arenas with a strong conversational and practical presence. A cultural whirlwind may build on an unpredictable and startling personal threat, as in the extension of the hot crisis surrounding BSE. Where a hot crisis deals with dread, risk, and accelerated political demands, a whirlwind tends to encompass a wider range of public arenas (i.e. not just the political) and have relevance for practical talk and actions that absorb public attention in an inexorable way. As well, a whirlwind effect can occur independent of a hot crisis, as illustrated in the whirlwind that built up around recycling in the late 1980 s.

Recycling was carried forward by a ripe issue climate and, at least for a short period, became an inescapable reality. The recycling bandwagon acquired replicating lives as it extended from schools through country fairs to talk shows, with communities, corporations and individuals vying to establish their green cre- dentials and extend blue box programs (Ungar 1998c). Environmentally safe or friendly packaging and products were suddenly ubiquitous and given prominent displays in stores. People routinely carried cloth bags or brought their own plastic ones, and supermarkets offered discounts to these customers. Ultimately, this whirlwind of attention had real long-term effects, though by focusing on recycling it may well have diverted attention from more significant issues.

Convenient bridging metaphors, good timing, and fortuitous events all converged to create a whirlwind around the ozone problem. The ozone hole created a hot crisis and asserted itself in the public realm even before scientists definitively concluded that it was due to anthropogenic activities. In this regard, Grundmann (2001, p. 170-171) associates the ozone hole with 'alarm bells [that] were sounded behind the scenes', and a 'sledge-hammer', and indicates that it 'was absolutely crucial in reaching the compromise [in Montreal].' While the critical precipitating role of the ozone hole is central to the present analysis, it lies largely outside the theoretical model of advocacy used by Grundmann. And while he does claim that advocacy scientists had to turn this finding into a dramatic phenomenon, just how and when this was done remains puzzling. ${ }^{7}$ In contrast, the analysis here links the ozone hole to the popular culture and public reactions. After all, the policy process sometimes occurs in the public spotlight.

This second coming of the ozone threat resulted in successful boycotts of companies using Styrofoam ${ }^{\circledR}$ in food packaging. It is probably critical here that these products were 'touchable', involving tangible links with everyday life. ${ }^{8}$ In contrast, the public paid little attention to scientists' concerns that increased ultraviolet radiation would harm the human immune system, as well as plant and aquatic life (here linkages are attenuating, as are the bridging metaphors). However, deeper anxieties and a spiraling concern emerged over the threat of skin cancer, as well as unsubstantiated reports about animals blinded by the sun (Ungar 1998a).

The principal hazard that came to be associated with leakage through the ozone shield was melanoma, a deadly form of skin cancer. The ensuing progression of events was superb, as President Reagan had skin cancers removed in 1985 and 1987. At the same time, as the end of the Cold War erased the major source of

\footnotetext{
${ }^{7} \mathrm{~A}$ key problem for Grundmann is to explain how the Reagan administration's severe downplaying of environmental concerns was reversed in the mid-1980s. He offers no real explanation for this inversion, certainly nothing on the level of the cultural whirlwind presented here

${ }^{8}$ It also did not hurt that people gave up essentially nothing in giving them up (cf. Ungar 1998c)
} 
anxiety in American society, the popular culture commercialized a variety of disasters, including new diseases, earthquakes, volcanoes, hurricanes and tornadoes (Colt 1997). Ozone loss meshed nicely with this disaster boom. Not only is it linked to the theory that a comet striking Earth extinguished the dinosaurs, but it transforms routine exposure to sunlight (or simply being outdoors) into a potentially dangerous activity.

Here it should be underlined how the rapid sequence of events surging through different arenasboycotts, the Montreal Protocols, President Reagan's skin cancers, medical warnings, and political gaffesserved to unleash a whirlwind around the issue. Blunder and luck solidified the personal relevance of this threat. US Interior Secretary Donald Hodel misjudged the public mood when he advocated a 'personal protection' plan in the place of international action on the issue (Litfin 1994, p. 105-106). Not only was his suggestion immediately mocked ('fish don't wear sunglasses'), but the gaffe has become a sticky resource. That is, his mindless statement is frequently referenced and is a ready-made available tool for building a case for protection of the ozone level.

But the ozone threat ultimately became intrusive and irresistible because of the imperative of dealing with exposure to the sun. Warnings about (over) exposure became commonplace in stories and advertisements in family and women's magazines. Metaphors about 'safe sun' were boosted by the growth of a companion industry encompassing sunscreens, sunglasses, UVsafe clothing, awnings, and so on. The inclusion of an UV index in weather reports underscored the need for vigilance. So too did reports of increased rates of skin cancer, plus medical warnings to watch for skin changes and inspect moles.

The problem became a fertile source of interest, anxiety, and practical knowledge, talk and action as it redounded on the need to protect children (Ungar 1998a). This is an issue that people can discuss without feeling overwhelmed or stupefied. It also calls for constant vigilance. The sun's rays can often be 'felt', and (unexpected) sunburns afford palpable evidence of their (now dangerous) effects.

As previously noted, there are apparently no readymade popular cultural metaphors that provide simple schematics for understanding and concretizing climate change. The upshot is that climate change does not afford an appropriable theory that people can think or talk with, nor does it intrude into their daily lives in concrete and persistent ways. At the practical level, many North Americans have seemingly insulated themselves from heat waves by the spread of air conditioning (it comes as standard equipment in over $90 \%$ of cars manufactured in North America) and swimming pools. At the conversational level, climate change engenders a persistent backlash (and then, too often, speech vetoes) as the issue is cast in terms of simplistic cultural models. Consider the question of meeting the commitments made at Kyoto, and how this meshes with cultural givens about the high costs of energy efficiency.

Perusal of the Kyoto debate in North American media yields a lopsided discussion. Excepting a few op-ed articles and technical reports in specialized journals, public discourse simply assumes that efforts to reduce carbon dioxide emissions will cause personal suffering, job losses, reduced international competitiveness, and possibly a recession (Ungar 1998a, 1999). As part of the dominant institutional thinking, the high-cost argument functions as a convenient and comfortable fiction, a trusty and almost axiomatic resource that is presented as an indisputable reality. Those who try to present cost-efficiency arguments in mainstream arenas mostly encounter silence. Altogether, then, the meshing of the Kyoto reductions with the institutionally embedded high-cost argument implies that the agreement will continue to encounter a rough ride in the policy stream.

\section{CONCLUSION}

As I write this, floods are threatening Prague, Dresden, and other historic cities in Europe. Parts of Asia have also experienced extreme monsoon floods, while the Canadian prairies are in the midst of such an extended drought that many farmers are being forced to slaughter their cattle. Toronto has experienced its hottest summer on record. And earlier in the summer, there were several massive forest fires in Canada and the US.

Any possible association between the weather and climate change has been reduced to a set piece. According to the New York Times (Green 2002):

'Greenpeace and other environmental groups tried to portray the flooding as a direct consequences of human-caused global warming, blaming oil companies. Many scientists said that the summer storms... are consistent with rainfall patterns expected in a warming climate... But experts stressed that no single storm, or single stormy season for that matter, could be singled out as linked to human alteration of the atmosphere.'

Effectively, postnormal science, operating under conventional rules of scientific evidence, is all but reduced to silence.

These events are also not meshing with a congenial issue culture. Two problems dominate US public arenas: first, the threat of terrorism (the anniversary of 9/11 is coming around) and a possible war on Iraq; 
second, the economy, including job losses, the falling stock market and corporate financial scandals. Two big issues are almost one too many in the US. Barring weather impacts on a scale I will not conjecture, weather and global warming will remain as sidebars in the media arena and nonstarters in the policy arena.

These liabilities cannot be whisked away by more adept claimsmaking. Rather, it seems that a key problem in North America is ignorance related to both science and policy. Besides the misapprehension of energy efficiency previously discussed, ideas such as the precautionary principle and a no-regrets policy have virtually no standing in the dominant discourse. Superimposed on any environmental talk is economic talk, and the latter, in the form of a free-market/lowgovernment interference mantra, invariably trumps the former. Thus the recycling whirlwind was hijacked by industry, resulting in very circumscribed policy

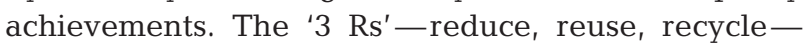
were reduced to the last one alone, with industry and public discourse actively opposing reuse, and a whole culture and economy set tight against any idea of reduction (Ungar 1998c). In the last few years, New York City, to name one of a number of places, has cutback on recycling programs because they proved to be costly rather than turn a profit.

Are there avenues we are missing? Probably the most concerted actions to combat climate change have come at local levels, especially cities. Yet the paradoxes of global warming become more prickly here, since the global circulation models are not sufficiently advanced to make accurate regional predictions. Hence the idea of getting people to 'visualize' climate change on a regional level-the author is currently examining the role of visualization in social problems runs up against the limits of science. Still, it is at the local level that problems such as air pollution and smog can be linked, in a 'no-regrets' strategy, to climate issues.

Finally, there is the possibility of borrowing from campaigns to reduce smoking. Assessment of these campaigns suggest that those which target individual smokers are less successful than those that target the behaviour of tobacco firms (Picard 2002). The latter employ what are called 'tobacco-industry denormalization' strategies. These range from evidence that the industry deliberately misled the public about risks, to its attempts to promote smoking among the young despite claims to the contrary. Now American industry has suffered a loss of legitimacy due to faulty accounting and various 'off the balance sheet' land mines. With global warming, companies could eventually face unexpected expenses because of compliance with future regulations, fines, taxes and possible caps on products that produce greenhouse gases. An 'Enron effect' could also affect companies that fail to protect themselves from climate-related risks. Increasing numbers of shareholders have begun to demand that companies take into account potential environment liabilities, and governments may use the precedent of tobacco litigation to sue corporations for pollution (Cortese 2002). With an issue culture challenging industry and a long history of using the legal arena to redress social problems, this may well be an outlet for commanding action and educating the public.

Acknowledgements. The author would like to thank Malcolm MacKinnon and Bev Craven for comments on earlier versions of the manuscript.

\section{LITERATURE CITED}

Bernard H (1993) Global warming unchecked: signs to watch for. Indiana University Press, Bloomington

Bray D, von Storch H (1999) Climate science: an empirical example of postnormal science. Bull Am Meteorol Soc 80:439-455

Clemens E (1986) Of asteroids and dinosaurs: the role of the press in the shaping of scientific debate. Social Stud Sci 16:421-456

Cline W (1992) The economics of global warming. Institute for International Economics, Washington

Colt G (1997) The strange allure of disasters. Life, June, p 58-75

Cortese A (2002) As the earth warms, will companies pay? New York Times, August 18, p A1

Dunlap R, Scarce R (1991) The polls-poll trends: environmental problems and protection. Public Opinion Q 55: 651-672

Fritz N, Altheide D (1987) The mass media and the social construction of the missing children problem. Sociol Q 28: 473-492

Green P (2002) Tens of thousands flee Prague as flood invades historic center. New York Times, August 14, p A1

Grundmann R (2001) Transnational environmental policy: reconstructing ozone. Routledge, London

Hannigan J (1995) Environmental sociology: a social constructionist perspective. Routledge, London

Kempton W, Boster J, Hartley J (1995) Environmental values in American culture. MIT Press, Cambridge

Litfin K (1994) Ozone discourses: science and politics in global environmental cooperation. Columbia University Press, New York

Mazur A, Lee J (1993) Sounding the global alarm: environmental issues in the U.S. national news. Social Stud Sci 23:681-720

McCombs M, Shaw D (1993) The evolution of agenda-setting research: twenty-five years in the marketplace of ideas. J Commun 43:58-67

Parson E (1993) Protecting the ozone layer. In: Haas P, Keohane R, Levy $M$ (eds) Institutions for the earth: sources of effective international environmental protection. MIT Press, Cambridge, p 27-73

Picard A (2002) Antismoking campaign ineffective. Globe and Mail, August 19, p A6

Rowlands I (1995) The politics of global atmospheric change. Manchester University Press, Manchester

Schneider S (1989) Global warming: are we entering the greenhouse century? Sierra Club Books, San Francisco 
Tagliabue J (1998) Europe takes to the road in a small way. New York Times, April 21, p C1

Turkle S (1999) Looking toward cyberspace: beyond grounded sociology. Contemp Sociol 28:643-648

Ungar S (1990) Moral panics, the military industrial complex, and the arms race. Sociol Q 31:165-185

Ungar S (1991) Civil religion and the arms race. Can Rev Sociol Anthropol 28:503-525

Ungar S (1992a) The rise and (relative) decline of global warming as a social problem. Sociol Q 33:483-501

Ungar S (1992b) The rise and fall of nuclearism: fear and faith as determinants of the arms race. Penn State Press, University Park, PA

Ungar S (1995) Social scares and global warming: beyond the Rio Convention. Soc Nat Resour 8:443-456

Ungar S (1996) Is global warming still worth a blip? A study of media coverage in three countries. Delta 7:6-15

Ungar S (1998a) Bringing the issue back in: comparing the

Editorial responsibility: Hans von Storch,

Geesthacht, Germany marketability of the ozone hole and global warming. Social Problems 45:510-527

Ungar S (1998b) Hot crises and media reassurance: a comparison of emerging diseases and Ebola Zaire. Br J Sociol 49:36-56

Ungar S (1998c) Recycling and the dampening of ecological concern: the role of large and small actors in shaping the environmental discourse. Can Rev Sociol Anthropol 35: 253-276

Ungar S (1999) Is strange weather in the air: a study of U.S. national news coverage of extreme weather events. Clim Change 41:133-150

Ungar S (2000) Knowledge, ignorance and the popular culture: climate change versus the ozone hole. Public Understand Sci 9:297-312

Ungar S (2001) Moral panic versus the risk society: the implications of the changing sites of social anxiety. Br J Sociol 52:271-291

Submitted: September 25, 2002; Accepted: December 7, 2002 Proofs received from author(s): February 10, 2003 